\title{
Rainy season characteristics for the Luvuvhu River catchment, South Africa
}

\author{
Fhulufhelo Phillis Tshililo ${ }^{1,2 *}$, Michael John Savage ${ }^{2}$ and Mokhele Edmond Moeletsi ${ }^{1,3}$ \\ ${ }^{1}$ Agricultural Research Council - Soil, Climate and Water, Private Bag X79, Pretoria 0001, South Africa \\ ${ }^{2}$ Soil-Plant-Atmosphere Continuum Research Unit, University of KwaZulu-Natal, Private Bag X01, Scottsville 3209, South Africa \\ ${ }^{3}$ Risk and Vulnerability Assessment Centre, University of Limpopo, Private Bag X1106, Sovenga 0727, South Africa \\ ${ }^{*}$ Current affiliation: Developmental, Capable and Ethical States, Human Sciences Research Council, Pretoria, South Africa
}

Maize is a staple crop in South Africa and is mainly grown under rain-fed conditions. Rain-fed agricultural production is heavily reliant on rainfall during the planting season. Information on rainy season characteristics is of utmost importance as it guides farmers in preparing for the upcoming season. The study investigated rainy season characteristics for the Luvuvhu River Catchment with reference to rain-fed maize production. Historical daily rainfall data were obtained from 12 weather stations for the period 1923-2015. Instant+ statistical software was used to compute onset, false onset, cessation and length of the rainy season. The trends in rainy season characteristics were analysed using the Spearman rank correlation test. Onset of the rainy season can be expected from the first week of October to the third week of January, while cessation can be expected from the first week of February to the first week of May. The length of the rainy season ranged from 67 to 203 days. Seasonal rainfall ranged from 182 to $1535 \mathrm{~mm}$. Phafuri, Sigonde, Phunda Maria and Folovhodwe had a higher probability of false onset. No significant changes in rainy season characteristics at a $5 \%$ level of significance were observed. There was a strong correlation between onset and length of the rainy season. Based on rainfall patterns only, Phafuri, Sigonde and Folovhodwe might not be suitable for maize production under the current climate. The most favourable sites for maize production within the catchment are Entabeni, Levubu, Lwamondo, Thathe, Tshiombo and Vreemedeling. The findings of this study have implications on agricultural activities and food security as maize is a staple crop in the Luvuvhu River catchment area. Information on rainy season characteristics may therefore help in strengthening food security.

\section{INTRODUCTION}

Globally, food production is highly dependent on rain-fed agriculture and produces more than $60 \%$ of the world's cereal grains (Molden et al., 2011). Rain-fed agriculture is practised in about $80 \%$ of the cultivated lands (Bhattacharya, 2019). According to Asseng and Pannell, (2013) rainfall variability is the primary source of variability in grain yields. A study by Pachauri et al. (2014) revealed that there have been changes in seasonal rainfall patterns, which include onset, duration of rains, frequency of dry spells, rainfall intensity and delays in the onset of rainfall in southern Africa. Regardless of the increase in fertilizer use and improved agricultural technologies, climate still plays a significant role in agricultural production. Even though different climatic variables interact with the crop, rainfall pattern and amount of rainfall are the most critical factors that affect agriculture (Nkuna and Odiyo, 2016; Stern and Coe, 1984) and more so for the semi-arid catchments. Successful maize production depends on adequate rainfall since the amount of rainfall received determines the type of agriculture that can be practised and the type of crops grown in any region (Hassan and Stern, 1988; Stern et al., 1982). Other factors influencing the choice of crops grown in any area include economic and social factors such as cultural practices and traditions.

The rainy season is defined as the period when a significant amount of rainfall occurs and can vary from place to place (Smith et al., 2008). The rainy season characteristics that are important to maize production are onset, cessation, length of the growing season, rainfall amount and dry spells, thus influencing the choice of the cultivars (Hassan and Stern, 1988; Tadross et al., 2007). Delayed onset extends the growing period of summer crops into the winter season (Mubvuma, 2013), leading to crop failure and reduced yield (Gbangou et al., 2019). Planting after a false early onset may result in crop failure, which leads to expensive re-planting (Ayoade, 2004; Dunning et al., 2016). Information regarding the rainy season's onset can help farmers plan agricultural activities such as preparation of land, seeds, labour and equipment (Omotosho et al., 2000). Another important feature of the rainy season is the end of the season; if the end of the season occurs early, the crops might experience low cob development resulting in a poor harvest (Stern and Coe, 1984).

Information on cessation of the rainy season also helps to assess the possible length of the rain-fed cropping season and provides information on optimal harvesting and storage of crops (Hachigonta et al., 2008). Heavy rainfall at the end of the season can cause crops to spoil or prevent ripening and harvesting (Stern and Coe, 1984). Yield may be significantly affected by late-onset or early cessation of the season and damaging dry spells during the season (Ati et al., 2002; Mugalavai et al., 2008). If farmers are provided with information on the seasonal distribution of rainfall, they can choose to plant either more drought-tolerant crops or longer maturing varieties (Tadross et al., 2005), and such strategic planning is important in semi-arid areas. Farmers rely on seasonal forecasts to plan for the upcoming season.

\section{CORRESPONDENCE}

Fhulufhelo Phillis Tshililo

\section{EMAIL}

Ftshililo@gmail.com

\section{DATES}

Received: 16 November 2018

Accepted: 24 September 2021

\section{KEYWORDS}

cessation

dry spells false onset

onset

maize production

\section{COPYRIGHT}

() The Author(s)

Published under a Creative Commons Attribution 4.0 International Licence (CC BY 4.0) 
However, seasonal forecasts do not include information on rainy season characteristics, which are important to farmers.

Maize is the largest locally produced crop (Ambrosino et al., 2014) and is the primary staple food in South Africa, accounting for around $70 \%$ of caloric human intake (Akpalu et al., 2008; Martin et al., 2000). Maize is grown extensively under rain-fed conditions in the Southern African Development Community (SADC) region, including South Africa (Durand, 2006). The main objective of this study was to investigate the temporal variability of rainy season characteristics (onset, cessation, length of the rainy season and seasonal rainfall) of selected locations in the Luvhuvhu River catchment area in the context of its suitability for rain-fed maize production.

\section{MATERIALS AND METHODS}

\section{Study area}

The study was conducted at selected areas within the Luvuvhu River catchment. The Luvuvhu River catchment is located in the north-eastern region of South Africa in the Limpopo Province, between longitudes $29^{\circ} 49^{\prime} 46.16^{\prime}$ " and $31^{\circ} 23^{\prime} 32.02$ ' $\mathrm{E}$ and latitudes $22^{\circ} 17^{\prime} 33.57^{\prime \prime}$ and $23^{\circ} 17^{\prime} 57.31^{\prime \prime} \mathrm{S}$ (Fig. 1). The catchment forms part of the Luvuvhu/Letaba Water Management area. The climate varies spatially and temporally and is classified as humid subtropical according to the Köppen-Geiger climate classification (Conradie, 2012). The catchment experiences wet summers from October to April (Singo et al., 2012) and receives peak rainfall in January and February (ARC, 2015). The topography influences rainfall in the catchment, with high rainfall and low evapotranspiration occurring over the Soutpansberg mountain range and lowest rainfall and high evapotranspiration in the arid areas along the east of the catchment adjacent to the Kruger National Park (Jewitt et al., 2004). The catchment receives rainfall of about $450 \mathrm{~mm}$ per annum in the low-lying areas (north and eastern parts) and $2300 \mathrm{~mm}$ at Entabeni in the Soutpansberg mountains (south-western and north-western parts) (DWAF, 2004) (Fig. 2). The mean annual precipitation is $608 \mathrm{~mm}$, while the mean annual air temperatures are $17^{\circ} \mathrm{C}$ in mountainous areas and $24^{\circ} \mathrm{C}$ near the Kruger National Park (Singo et al., 2012). The altitude of the catchment ranges from $200 \mathrm{~m}$ in the low-lying areas to $2000 \mathrm{~m}$ in the mountainous areas (Odiyo et al., 2015). Vegetables, citrus and various subtropical fruits such as bananas, mangoes, avocadoes and nuts are grown and contribute to the economy (Masupha et al., 2016). More than $50 \%$ of the land in the catchment is used for subsistence farming (Jewitt et al., 2004), with farmers engaging in crop and livestock production as well as other activities, mainly for their own consumption.

\section{Rainfall data}

Daily historical rainfall data from 12 weather stations for the period from 1923/24 to 2014/15 were obtained from the Agricultural Research Council (ARC) databank. Only stations with data for a period of more than 25 years and little missing data were utilized in the study. Missing data were filled using the ARC patching program that utilizes the inverse distance weighting method (Moeletsi et al., 2016). The stations used in the study are shown in Table 1 and Fig. 1. They were spatially distributed across the catchment and were representative of different climatic conditions within the catchment.

\section{Determination of rainy season characteristics}

The onset of the rainfall season was determined based on a study conducted by Tadross et al. (2007), which defined onset as the first day after 1 October when the rainfall accumulated in 10 days is at least $25 \mathrm{~mm}$ (Tadross et al., 2007). Not all farmers plant after the first rainfall for several reasons, such as unavailability of tractors, workforce and inputs (Masupha et al., 2016), and oversaturated soil makes it difficult for tractor ploughing. Therefore, 3 onset dates were generated for each station. The second and third onset dates were calculated 7 days after the previous onset. The definition used to define the onset was for farmers; hence, no criteria for false onset were introduced to account for false onset. Ati et al. (2002) and Ambrosino et al. (2014) argued that the criteria for avoiding false onset, such as that used by Reason et al. (2005), Mupangwa et al. (2011), Moeletsi and Walker (2012), Tongwane and Moeletsi (2015) and Masupha et al. (2016). are useful for retrospective analysis only and of no use to farmers. Farmers plant after the first significant rainfall irrespective of what might occur in the following days.

The risk of the first onset date being a false onset was calculated by introducing a further criterion. Thus, to account for false onset, onset was defined as the first day after which $25 \mathrm{~mm}$ or more of rainfall accumulates in 10 days and when in the following 20 days, $20 \mathrm{~mm}$ of rainfall is accumulated (Tadross et al., 2007). Results obtained using the two definitions were then compared. This study assumed that planting would have failed if, in the following 20 days, the amount of rainfall was less than $20 \mathrm{~mm}$ for that year. For example, if results generated by the two definitions were different, then planting would have failed in that particular year. The percentage of failure was determined for all stations within the catchment.

Cessation was defined as 3 consecutive dekads (10-day periods) of less than $20 \mathrm{~mm}$, each occurring after 1 February, following the exact definition by Tadross et al. (2007). The length of the rainy season was calculated by subtracting the first onset date from the cessation date.

Table 1. Geographical information for the twelve weather stations used in the study

\begin{tabular}{lccccc}
\hline Station & Latitude $\left({ }^{\circ} \mathrm{E}\right)$ & Longitude $\left({ }^{\circ} \mathrm{S}\right)$ & Elevation $(\mathrm{m})$ & Data period & Average annual rainfall $(\mathrm{mm})$ \\
\hline Elim & -23.17 & 30.05 & 808 & $1945-2004$ & 732 \\
Entabeni & -23.00 & 30.27 & 1376 & $1923-2012$ & 1735 \\
Folovhodwe & -22.53 & 30.48 & 610 & $1954-2004$ & 356 \\
Levubu & -23.04 & 30.15 & 877 & $1986-2015$ & 1356 \\
Lwamondo & -23.04 & 30.37 & 650 & $1978-2015$ & 865 \\
Mampakuil & -23.17 & 29.00 & 945 & $1945-2004$ & 497 \\
Phafuri & -22.42 & 31.22 & 201 & $1970-2004$ & 464 \\
Phunda Maria & -22.68 & 31.02 & 462 & $1945-2004$ & 526 \\
Sigonde & -22.40 & 30.71 & 416 & $1983-2015$ & 421 \\
Thathe & -22.88 & 30.32 & 1250 & $1963-2004$ & 1172 \\
Tshiombo & -22.80 & 30.48 & 650 & $1983-2009$ & 986 \\
Vreemedeling & -22.96 & 30.01 & 1421 & $1945-2004$ & 801 \\
\hline
\end{tabular}




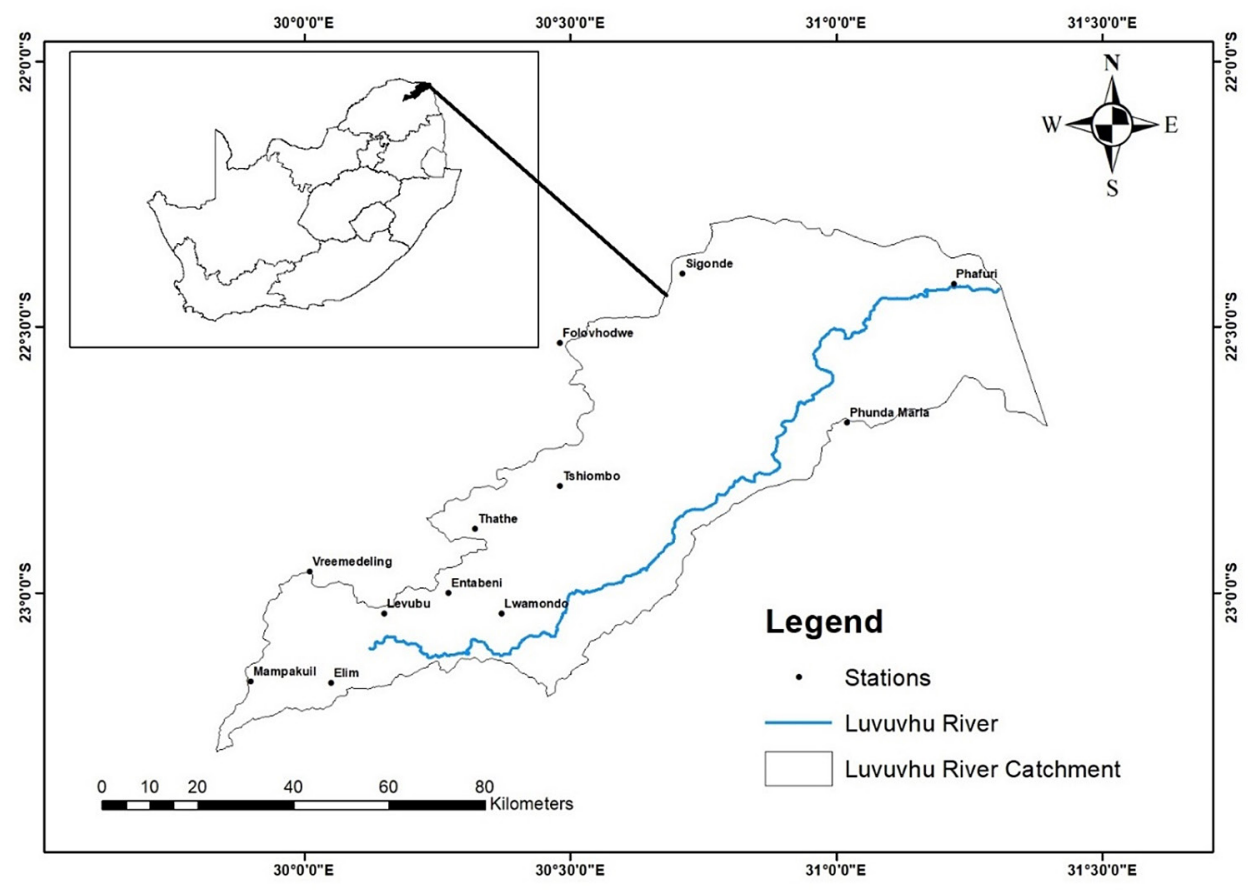

Figure 1. Map of the study area showing the location of the weather stations

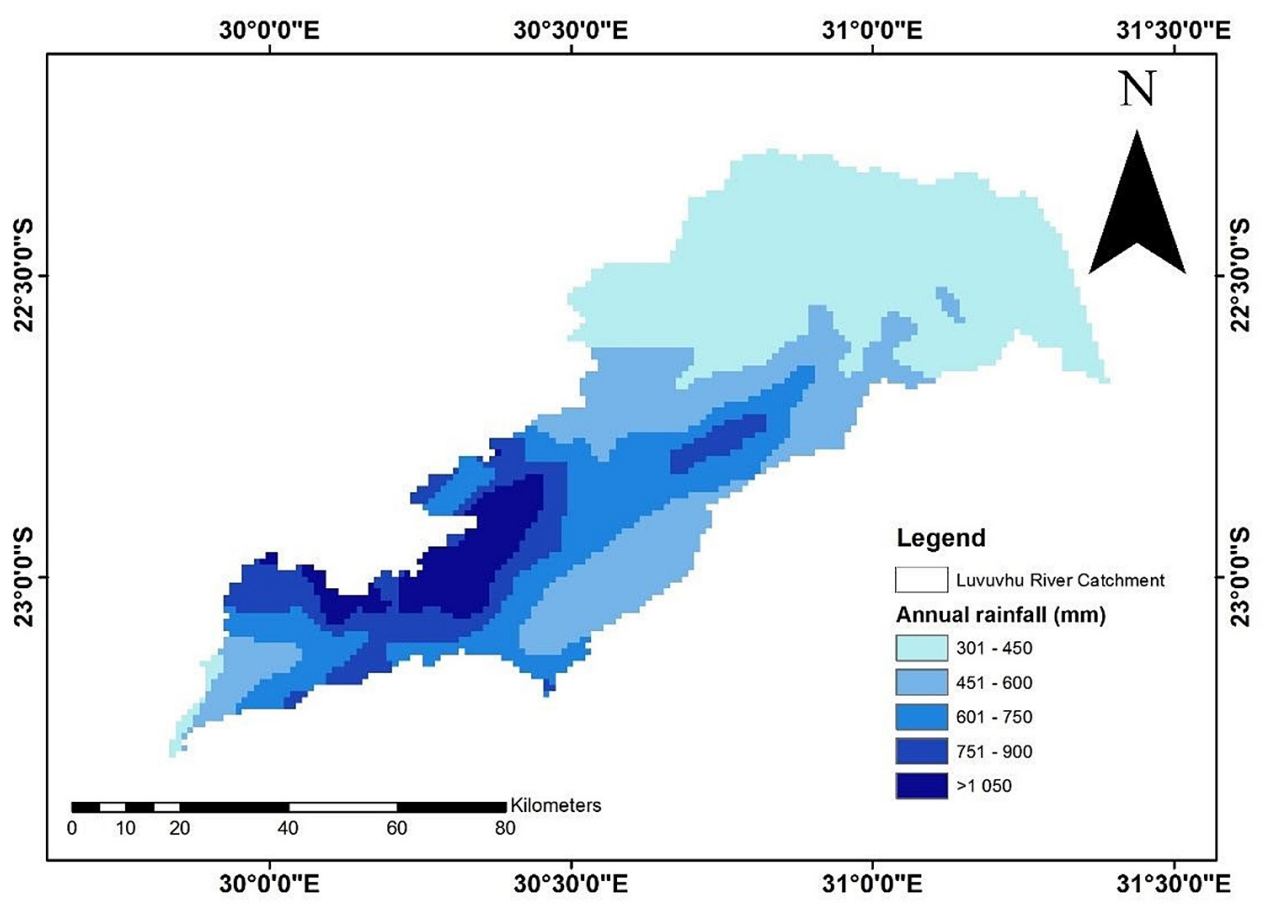

Figure 2. Annual rainfall for the Luvuvhu River catchment

\section{Statistical analysis}

Instat $^{+}$V 3.36 (Statistical Services Centre, University of Reading, UK) was used to analyse daily rainfall data for onset, cessation and length of the rainy season, and false onset. Years in which the onset of rains occurred after 31 January were regarded as years in which rainfall did not meet the onset criterion; therefore, they were not included in further statistical analysis. Probabilities of exceedance and non-exceedance for rainy season characteristics were estimated using the STATISTICA (System GVP, Italy) statistical software. Non-exceedance probability represented the onset and the length of the rainy season, while the rainy season's cessation was represented by exceeding probability. Probabilities were determined at 20,50 and $80 \%$. For onset, probabilities of nonexceedance at 20,50 and 80\% indicated early, normal and late onset.
For cessation, 80,50 and $20 \%$ probability of exceedance indicated early, normal and late cessation of the rainy season. Spearman rank correlation coefficient test was conducted to detect trends in rainy season characteristics over the years. The Spearman rank correlation coefficient is a non-parametric test used for evaluating the relationship between two independent variables (Gautheir, 2001). The Spearman rank was used because it is a non-parametric technique unaffected by the distribution of the data. The Spearman rank correlation was calculated using the following equation:

$$
r_{s}=1-\frac{6 \sum d_{i}^{2}}{n^{3}-n}
$$

where $d_{i}$ is the difference between ranks for each $x_{i}, y_{i}$ data pair, and $n$ is the number of data pairs. The value of $r_{s}$ can be any value between -1 and 1 (Puth et al., 2015). When the value of $r_{s}$ 
is equal to 1 , the data pairs have a perfect positive correlation $\left(d_{i}=0\right)$, and when it is -1 , there is a perfect negative correlation (Gautheir, 2001). A negative value indicates a decreasing trend and a positive value an increasing trend. For this study $r_{s}$ values will be interpreted as follows:

$$
\begin{aligned}
& \text { - } 0.0 \text { to } 0.2 \text { very weak } \\
& \text { - } 0.2 \text { to } 0.4 \text { weak } \\
& \text { - } 0.4 \text { to } 0.6 \text { moderate } \\
& \text { - } 0.4 \text { to } 0.8 \text { strong } \\
& \hline
\end{aligned}
$$

\section{RESULTS AND DISCUSSION}

\section{Onset of the rainy season}

Table 2 presents 3 generated onset dates. The first onset can be expected from the first week of October to the second week of December. At $50 \%$ probability of non-exceedance, onset can be expected to occur from the second week of October to the second week of November (Table 2). At $80 \%$ probability of non-exceedance, the first onset can be expected from the last week of October to the second week of December. Farmers might decide not to plant following the first onset due to several reasons: unavailability of tractors, shortage of seeds, high soil moisture, and variation. The second onset can be expected from the third week of October to the last week of December. At 20\% probability of non-exceedance, the second onset occurs from the third week of October to the second week of November. At $50 \%$ probability of nonexceedance, the second rains for the season can be expected from the last week of October to the first week of December (Table 2). The third onset can be expected in the last week of October through to the third week of December. In 1 out of 5 years, the third onset can be expected from the last week of October to the first week of December at the catchment. In 1 out of 2 years, the third onset can be expected from the second week of November to the last week of December. In 4 out of 5 years, the third onset can be expected from the last week of December to the second week of January.

The rainy season starts early at Entabeni, Thathe, Levubu and Lwamondo, and later at Sigonde, Folovhodwe and Phafuri. Entabeni, Levubu and Lwamondo and Tshiombo receive more than $700 \mathrm{~mm}$ of rainfall annually, while Sigonde, Folovhodwe, Phunda Maria and Phafuri receive less than $500 \mathrm{~mm}$ annually (Table 1). Early onset was observed in wet areas and late onset in arid rainfall areas. These results corroborate those of Aviad et al. (2004), Mupangwa et al. (2011) and Byakatonda et al. (2020), which revealed that the onset of the rainy season commences later as aridity increases. Onset varied by nearly a month between wet and dry regions of the catchment, demonstrating farmers in wet areas plant maize a month earlier than farmers in arid areas of the catchment.

A study by Moeletsi and Walker (2012) revealed that dates corresponding to $20 \%$ probability of non-exceedance have a high probability of onset failure and maize being planted. Thus farmers are advised not to plant on dates corresponding to $20 \%$ probability of non-exceedance. Raes et al. (2004) stated that planting later in the season on dates corresponding to $80 \%$ probability of nonexceedance reduced crop failure risk, but early maturing varieties are recommended as planting later in the season shortens the maturing period. Farmers who intend to sell their maize for high profit can plant early on dates corresponding to $20 \%$ probability of non-exceedance, provided they have alternative sources of water such as rainwater harvesting technologies and irrigation systems. Farmers sell maize at high prices before it is more readily available (Raes et al., 2004). A study by Masupha et al. (2016) investigating the probabilities of dry spells indicated that when planting is done after the second and third onset, there is a low probability of medium-dry spells in the Luvuvhu River catchment. Therefore, planting following the second onset of rains is advised.

The first onset should be used for planning purposes, gathering tools, seeds and workforce. Table 3 shows the number of years with false onset for the years analysed. Levubu had $0 \%$ risk of false onset occurrence; therefore, maize planted at Levubu is less prone to shortages of soil water at any planting date after significant rains (Table 3). Phafuri had the highest number of years with false onset, while Entabeni had relatively low chances (4\%). At Phafuri, planting failed in 18 out of 34 years (Table 3 ). Therefore, the risk of false onset is estimated to be $55 \%$, and the area has a high risk of crop failure when planting after the first onset. For other years in which planting would have failed, farmers had to wait between 33 and 71 days for successful planting. At Sigonde, Lwamondo and Tshiombo, farmers had to wait 29 to 64 days before successful planting, suggesting high vulnerability in these areas. If farmers had planted in those years with false onset, it would have resulted in total crop failure and necessitated expensive re-planting. Therefore, farmers at Phafuri and Sigonde are advised not to plant after the first onset, as there is a high risk of crop failure. However, if farmers in these areas wish to plant after the first onset, they should explore other options such as rainwater harvesting so that the crop has sufficient water during dry spells. The number of years with false onset increases as one moves from stations situated in high rainfall areas to arid areas. There were no significant changes in all onset dates across the catchment at 5\% level of significance (Table 4). At the $10 \%$ level of significance, there was a significant increasing

\begin{tabular}{|c|c|c|c|c|c|c|c|c|c|c|c|c|}
\hline \multirow[b]{2}{*}{ Stations } & \multicolumn{4}{|c|}{ First onset } & \multicolumn{4}{|c|}{ Second onset } & \multicolumn{4}{|c|}{ Third onset } \\
\hline & Early & Normal & Late & STD (days) & Early & Normal & Late & STD (days) & Early & Normal & Late & STD (days) \\
\hline Elim & $11 / 10$ & $19 / 11$ & $09 / 12$ & 16 & $29 / 10$ & $15 / 11$ & $01 / 12$ & 16 & $13 / 11$ & $02 / 12$ & $15 / 12$ & 12 \\
\hline Entabeni & $06 / 10$ & $13 / 10$ & $22 / 10$ & 11 & $18 / 10$ & $30 / 10$ & $12 / 11$ & 12 & $03 / 11$ & $13 / 11$ & $26 / 11$ & 11 \\
\hline Folovhodwe & $18 / 11$ & $11 / 11$ & $09 / 12$ & 21 & $08 / 11$ & $05 / 12$ & $28 / 12$ & 16 & $01 / 12$ & $28 / 12$ & $18 / 01$ & 13 \\
\hline Levubu & $06 / 10$ & $13 / 10$ & $24 / 10$ & 11 & $19 / 10$ & $28 / 10$ & $14 / 11$ & 11 & $31 / 10$ & $11 / 11$ & $27 / 11$ & 10 \\
\hline Lwamondo & $06 / 10$ & $19 / 10$ & $09 / 11$ & 18 & $19 / 10$ & $11 / 11$ & $28 / 11$ & 16 & $31 / 10$ & $22 / 11$ & $12 / 12$ & 15 \\
\hline Mampakuil & $16 / 10$ & $03 / 11$ & $21 / 11$ & 16 & $06 / 11$ & $24 / 11$ & $14 / 12$ & 14 & $24 / 11$ & $10 / 12$ & $28 / 12$ & 12 \\
\hline Phafuri & $13 / 10$ & $04 / 11$ & $08 / 12$ & 21 & $12 / 11$ & $03 / 12$ & $01 / 01$ & 18 & $29 / 11$ & $25 / 12$ & $17 / 01$ & 13 \\
\hline Phunda Maria & $19 / 10$ & $03 / 11$ & $25 / 11$ & 16 & $11 / 11$ & $24 / 11$ & $18 / 12$ & 12 & $28 / 11$ & $20 / 12$ & $15 / 01$ & 14 \\
\hline Sigonde & $20 / 11$ & $14 / 11$ & $07 / 12$ & 18 & $07 / 11$ & $03 / 12$ & $08 / 12$ & 17 & $28 / 11$ & $13 / 12$ & $16 / 01$ & 13 \\
\hline Thathe & $08 / 10$ & $15 / 10$ & $30 / 10$ & 17 & $20 / 10$ & $04 / 11$ & $16 / 11$ & 14 & $02 / 11$ & $15 / 11$ & $03 / 01$ & 14 \\
\hline Tshiombo & $12 / 10$ & $24 / 10$ & $04 / 11$ & 15 & $16 / 10$ & $11 / 11$ & $25 / 11$ & 14 & $13 / 11$ & $27 / 11$ & $19 / 12$ & 11 \\
\hline Vreemedeling & $12 / 10$ & $21 / 10$ & $09 / 11$ & 13 & $03 / 11$ & $17 / 11$ & $02 / 12$ & 13 & $18 / 11$ & $03 / 12$ & $19 / 12$ & 12 \\
\hline
\end{tabular}
trend at Phafuri $\left(r_{s}=0.34\right)$ for the third onset, indicating that the onset of rains has shifted forward by a few days for this area.

Table 2. Early (20\%) probability of non-exceedance, normal (50\%), and late (80\%) onset dates for 12 meteorological stations within the Luvuvhu River catchment 
Table 3. Number of years with false onset at stations within the Luvuvhu River catchment

\begin{tabular}{|c|c|c|c|}
\hline Stations & No. of years with false onset & No. of years analysed & Percentage (\%) \\
\hline Entabeni & 4 & 90 & 4 \\
\hline Levubu & 0 & 34 & 0 \\
\hline Lwamondo & 9 & 38 & 23 \\
\hline Tshiombo & 7 & 27 & 26 \\
\hline Phafuri & 18 & 34 & 55 \\
\hline Sigonde & 10 & 32 & 31 \\
\hline Mampakuil & 15 & 59 & 25 \\
\hline Elim & 16 & 59 & 27 \\
\hline Thathe & 5 & 40 & 13 \\
\hline Phunda Maria & 20 & 59 & 34 \\
\hline Folovhodwe & 19 & 59 & 32 \\
\hline Vreemedeling & 20 & 59 & 28 \\
\hline
\end{tabular}

Table 4. Spearman rank correlation coefficient test results for first, second and third onsets within the Luvuvhu River catchment

\begin{tabular}{|c|c|c|c|c|c|c|c|c|c|}
\hline \multirow{2}{*}{$\begin{array}{l}\text { Stations } \\
\text { Spearman rank }\end{array}$} & \multicolumn{3}{|c|}{ First onset } & \multicolumn{3}{|c|}{ Second onset } & \multicolumn{3}{|c|}{ Third onset } \\
\hline & t-stat & $p$-value & $r_{s}$ & t-stat & $p$-value & $r_{s}$ & t-stat & $p$-value & $r_{s}$ \\
\hline Elim & -0.64 & 0.52 & -0.08 & -1.03 & 0.30 & -0.13 & 0.05 & 0.95 & 0.00 \\
\hline Entabeni & 0.25 & 0.79 & 0.02 & 1.07 & 0.28 & 0.11 & 0.75 & 0.45 & 0.08 \\
\hline Folovhodwe & -1.4 & 1.60 & -0.18 & -0.69 & 0.49 & -0.10 & 0.40 & 0.68 & 0.07 \\
\hline Levubu & 1.12 & 0.26 & 0.19 & 0.95 & 0.34 & 0.16 & -0.08 & 0.93 & -0.01 \\
\hline Lwamondo & 1.17 & 0.24 & 0.19 & 1.22 & 0.22 & 0.20 & 1.09 & 0.28 & 0.18 \\
\hline Mampakuil & -0.13 & 0.89 & 0.01 & 0.55 & 0.57 & 0.07 & 1.17 & 0.24 & 0.16 \\
\hline Phafuri & -0.20 & 0.84 & -0.03 & 0.96 & 0.34 & 0.18 & 1.77 & 0.08 & $0.34^{* *}$ \\
\hline Phunda Maria & -1.7 & 0.08 & -0.23 & 0.05 & 0.95 & 0.00 & 0.56 & 0.57 & 0.08 \\
\hline Sigonde & -0.88 & 0.38 & -0.16 & -1.08 & 0.28 & -0.29 & -0.05 & 0.95 & -0.01 \\
\hline Thathe & 1.13 & 0.26 & 0.18 & 0.23 & 0.81 & 0.03 & 0.93 & 0.35 & 0.15 \\
\hline Tshiombo & 0.59 & 0.55 & 0.11 & 1.00 & 0.32 & 0.19 & 0.30 & 0.76 & 0.06 \\
\hline Vreemedeling & -0.59 & 0.55 & -0.07 & -0.18 & 0.85 & -0.02 & -0.12 & 0.90 & -0.01 \\
\hline
\end{tabular}

${ }^{*}$ significant at 5\%, ${ }^{* *}$ significant at $10 \%$

\section{Cessation of the rainy season}

Cessation dates at 80,50 and $20 \%$ probability of non-exceedance are presented in Table 5. Cessation of the rainy season can be expected from the first week of February to the first week of May, depending on the location in the catchment (Table 5). At the $80 \%$ level of probability of exceedance, cessation of the rainy season can be expected after the first week of February at Folovhodwe, Phafuri, Phunda Maria, Mampakuil and Sigonde. According to Moeletsi and Walker (2012), early cessation can subject maize to a high risk of water stress. If a 120-day maize cultivar was planted in November it would not have reached maturity by the first week of February, indicating that in 4 out of 5 years maize will not reach maturity if late maturing varieties are planted. Late cessation $\left(20^{\text {th }}\right.$ percentile) is likely to occur after the last week of February at Folovhodwe and the first week of May at Entabeni and Levubu. At 80,50 and $20 \%$ probability of exceedance, cessation of the season is delayed by between 20 and 50 days when comparing dry and wet areas of the catchment, as wet areas of the catchment receive the last rains of the season later than the dry areas. The Spearman rank correlation coefficient test at the 5 and $10 \%$ level of significance revealed no significant trend in cessation dates at any stations except Entabeni and Tshiombo (Table 6). Although not significant, a weak decreasing trend $\left(r_{s}=-0.24\right)$ is evident at Entabeni, indicating that over the years the rainy season has been ending earlier by a few days, thereby shortening its length. An increasing trend $\left(r_{s}=0.36\right)$ is notable at Tshiombo, indicating that the rainy season has been ending later over the years (Table 6).

\section{Length of the rainy season}

At 20,50 and $80 \%$ probability of non-exceedance, the rainy season length ranges from 67 days at Folovhodwe to 203 days at Entabeni (Table 7). In 1 out of 5 years, the length of the rainy season will range from 67 days at Folovhodwe to 149 days at Entabeni. Maize generally requires an average rainy season of 120 days from planting until harvesting, depending on the cultivar (Hachigonta et al., 2008). The rainy season lasted less than 120 days at 20 and $50 \%$ probability of non-exceedance in 5 out of the 12 stations. Only short-term maturing varieties can be planted in these areas. Medium and late maturing maize should not be planted as the crop will suffer from a shortage of water due to the early cessation of rains. Maize should only be planted in these areas if there is an alternative source of water. Wet areas of the catchment experience a longer growing season than the dry areas. At, Levubu, Entabeni and Thathe, farmers can plant from early to late maturating varieties, depending on the date of planting, while farmers at Folovhodwe, Phafuri, Mampakuil and Sigonde are advised to only plant early maturing varieties. At Elim, Lwamondo, Tshiombo and Vreemedeling, farmers can plant very early-, medium- and late-maturing maize varieties, depending on the date of planting and yield expectations. At Folovhodwe, Phafuri, Phunda Maria and Sigonde, the rainy season length differs by more than 70 days when compared to Entabeni, which has a long rainy season. The length of the rainy season in the catchment deviates by more than 25 days at all stations, indicating high variability. The relationship between time and duration of the rainy season was not significant at all stations except for Entabeni, Phunda Maria and Thathe (Table 8). At Thathe and Entabeni a weak decreasing trend is notable over the years (Table 8). This implies that instead of planting longmaturing varieties, farmers might have to shift to early- and medium-maturing maize varieties. 
Table 5. Early (80\%) probability of exceedance, normal (50\%) and late (20\%) cessation dates and standard deviation (STD) for 12 meteorological stations within the Luvuvhu River catchment

\begin{tabular}{lcccc}
\hline Station & Early & Normal & Late & STD (days) \\
\hline Entabeni & $06 / 03$ & $08 / 04$ & $03 / 05$ & 33 \\
Levubu & $26 / 02$ & $01 / 04$ & $02 / 05$ & 31 \\
Lwamondo & $11 / 02$ & $16 / 03$ & $15 / 04$ & 28 \\
Tshiombo & $07 / 02$ & $02 / 02$ & $30 / 03$ & 28 \\
Phafuri & $01 / 02$ & $18 / 02$ & $07 / 03$ & 20 \\
Sigonde & $01 / 02$ & $21 / 02$ & $11 / 03$ & 17 \\
Mampakuil & $03 / 02$ & $24 / 02$ & $12 / 03$ & 21 \\
Elim & $17 / 02$ & $06 / 03$ & $02 / 04$ & 27 \\
Thathe & $28 / 02$ & $23 / 03$ & $16 / 04$ & 29 \\
Phunda Maria & $01 / 02$ & $20 / 02$ & $16 / 03$ & 22 \\
Folovhodwe & $01 / 02$ & $17 / 02$ & $28 / 02$ & 19 \\
Vreemedeling & $20 / 02$ & $11 / 03$ & $07 / 04$ & 26 \\
\hline
\end{tabular}

Table 7. Short (20\% probability of non-exceedance), normal (50\%) and long (80\%) length of the rainy season and standard deviation (STD)

\begin{tabular}{lcccc}
\hline Stations & Short & Normal & Long & STD (days) \\
\hline Elim & 112 & 135 & 169 & 34 \\
Entabeni & 149 & 177 & 203 & 35 \\
Folovhodwe & 67 & 92 & 132 & 38 \\
Levubu & 133 & 163 & 200 & 32 \\
Lwamondo & 114 & 146 & 175 & 37 \\
Mampakuil & 89 & 113 & 140 & 31 \\
Phafuri & 72 & 103 & 136 & 38 \\
Phunda Maria & 82 & 108 & 143 & 26 \\
Sigonde & 77 & 104 & 125 & 31 \\
Thathe & 127 & 153 & 186 & 38 \\
Tshiombo & 102 & 131 & 168 & 34 \\
Vreemedeling & 114 & 139 & 169 & 32 \\
\hline
\end{tabular}

\section{Seasonal rainfall}

Seasonal rainfall within the catchment ranges from 182 to 1973 $\mathrm{mm}$, depending on the location, and shows a high variability both spatially and temporally (Table 9). In dry years, seasonal rainfall ranges from 182 to $1079 \mathrm{~mm}$ at Folovhodwe and Entabeni, whilst in normal years it ranges from 268 to $1476 \mathrm{~mm}$. When above-normal rainfall is received $(80 \%$ probability of non-exceedance), maize production should be maximized by planting more areas using high-yielding cultivars. Only 5 out of 12 stations receive more than $500 \mathrm{~mm}$ of rainfall in dry years, while the number increases to 7 in normal years. Maize requires between 500 and $800 \mathrm{~mm}$ per season. For this reason, planting rain-fed maize in these regions might be risky as water requirements might not be met, and crop failure could occur. Our results show high seasonal rainfall variability across all stations within the catchment, with a standard deviation ranging from 198 to $559 \mathrm{~mm}$ at Folovhodwe and Entabeni (Table 9). Areas receiving less than $500 \mathrm{~mm}$ of rainfall can be planted with other summer crops that require less water, such as sorghum, millet, soybeans and beans. Farmers can then market those crops and use the proceeds to purchase maize. Farmers who decide to plant maize can practise rainwater harvesting as maize is their only staple food. These options can help supplement
Table 6. Spearman rank correlation coefficient test results for the cessation of the rainy season for the various stations within the Luvuvhu River catchment

\begin{tabular}{lccc}
\hline Station & t-stat & $p$-value & $r_{s}$ \\
\hline Elim & 0.45 & 0.64 & 0.06 \\
Entabeni & -2.34 & 0.02 & $-0.24^{*}$ \\
Folovhodwe & 0.25 & 0.79 & 0.03 \\
Levubu & 1.40 & 0.16 & 0.24 \\
Lwamondo & 0.11 & 0.91 & 0.01 \\
Mampakuil & -0.56 & 0.57 & -0.07 \\
Phafuri & -0.44 & 0.65 & -0.07 \\
Phunda Maria & 0.67 & 0.50 & 0.08 \\
Sigonde & 0.51 & 0.60 & 0.09 \\
Thathe & 0.13 & 0.89 & -0.02 \\
Tshiombo & 1.95 & 0.06 & $0.36^{* *}$ \\
Vreemedeling & 0.87 & 0.38 & 0.11 \\
\hline *significant at 5\%; ${ }^{* *}$ significant at 10\% & &
\end{tabular}

Table 8. Spearman rank correlation coefficient test results for the duration of the rainy season

\begin{tabular}{lccc}
\hline Station & t-stat & $p$-value & $r_{s}$ \\
\hline Elim & 10.16 & 0.24 & 0.15 \\
Entabeni & -2.20 & 0.02 & $-0.22^{*}$ \\
Folovhodwe & 1.36 & 0.17 & 0.18 \\
Levubu & 0.80 & 0.42 & 0.14 \\
Lwamondo & -0.47 & 0.63 & -0.07 \\
Mampakuil & -0.67 & 0.50 & -0.08 \\
Phafuri & -0.06 & 0.94 & -0.00 \\
Phunda Maria & 1.82 & 0.07 & $0.23^{* *}$ \\
Sigonde & 1.15 & 0.25 & 0.22 \\
Thathe & -2.19 & 0.03 & $-0.33^{*}$ \\
Tshiombo & 0.78 & 0.13 & 0.15 \\
Vreemedeling & 0.90 & 0.37 & 0.11 \\
\hline *significant at 5\%; ${ }^{* *}$ significant at 10\% & &
\end{tabular}

water for maize production during dry periods. At the $5 \%$ level of significance, there was no significant change in seasonal rainfall over time for most stations, except Lwamondo, Levubu and Entabeni (Table 10). At Levubu $\left(r_{s}=0.37\right)$ and Lwamondo $\left(r_{s}=0.36\right)$, a weak increasing trend is evident. Therefore, more water will be available for maize in these areas. For Entabeni, there is a decreasing trend $\left(r_{s}=-0.21\right)$, meaning that seasonal rainfall has been decreasing.

Multiple regression analysis between onset and cessation, onset and length of the season, and onset and seasonal rainfall was computed. Regression analysis revealed that the relationship between onset and cessation of the rainy season was not significant at the $5 \%$ level of significance for all stations (Table 11). There is a strong significant relationship between the onset and length of the rainy season at all stations except Levubu. Our study results are consistent with those of Sivakumar (1988) and Mupangwa et al. (2011), which showed a strong relationship between onset and length of the rainy season, wherein early onset leads to a longer season while delayed onset leads to a shorter season. Farmers are advised to plant maize cultivars depending on the time of onset, e.g., if the onset of the rainy season occurs earlier, farmers can plant medium- to late-maturing varieties, and if onset is delayed, they can plant very early maturing varieties. 
Table 9. Dry (20\% probability of non-exceedance), normal (50\%), wet (80\%), rainy seasonal rainfall $(\mathrm{mm})$ and standard deviation (STD)

\begin{tabular}{lcccc}
\hline Station & Dry & Normal & Wet & Standard deviation \\
\hline Elim & 406 & 600 & 876 & 284 \\
Entabeni & 1079 & 1476 & 1973 & 559 \\
Folovhodwe & 182 & 268 & 514 & 198 \\
Levubu & 787 & 1032 & 1535 & 489 \\
Lwamondo & 500 & 680 & 898 & 351 \\
Mampakuil & 279 & 439 & 592 & 198 \\
Phafuri & 270 & 369 & 661 & 229 \\
Phunda Maria & 308 & 429 & 767 & 236 \\
Sigonde & 252 & 357 & 528 & 196 \\
Thathe & 662 & 950 & 1343 & 523 \\
Tshiombo & 574 & 841 & 1150 & 422 \\
Vreemedeling & 499 & 690 & 895 & 274 \\
\hline
\end{tabular}

Table 10. Spearman rank correlation coefficient test results for the seasonal rainfall

\begin{tabular}{lccc}
\hline Station & t-stat & $\boldsymbol{p}$-value & $\boldsymbol{r}_{\mathrm{s}}$ \\
\hline Elim & -0.45 & 0.65 & -0.06 \\
Entabeni & -2.09 & 0.03 & $-0.21^{*}$ \\
Folovhodwe & -0.98 & 0.33 & -0.12 \\
Levubu & 2.27 & 0.02 & $0.37^{*}$ \\
Lwamondo & 2.32 & 0.02 & $0.36^{*}$ \\
Mampakuil & -1.06 & 0.29 & -0.13 \\
Phafuri & -0.50 & 0.62 & -0.08 \\
Phunda Maria & 0.82 & 0.41 & 0.11 \\
Sigonde & 0.85 & 0.40 & 0.15 \\
Thathe & -1.77 & 0.08 & $-0.27^{* *}$ \\
Tshiombo & 1.88 & 0.07 & $0.35^{* *}$ \\
Vreemedeling & -0.42 & 0.67 & -0.05 \\
\hline *significantat 5\% **significantat $10 \%$ & &
\end{tabular}

Table 11. Multiple regression analysis results

\begin{tabular}{|c|c|c|c|c|c|c|}
\hline \multirow[t]{2}{*}{ Stations } & \multicolumn{2}{|c|}{ Onset and cessation } & \multicolumn{2}{|c|}{ Onset and length of rainy season } & \multicolumn{2}{|c|}{ Onset and seasonal rainfall } \\
\hline & $R^{2}$ & $p$-value & $R^{2}$ & $p$-value & $R^{2}$ & $p$-value \\
\hline Elim & 0.01 & 0.4 & 0.41 & $0.00^{*}$ & 0.07 & $0.04^{*}$ \\
\hline Entabeni & 0.00 & 0.90 & 0.11 & $0.00^{*}$ & 0.01 & 0.31 \\
\hline Folovhodwe & 0.06 & 0.06 & 0.75 & $0.00^{*}$ & 0.03 & 0.19 \\
\hline Levubu & 0.01 & 0.52 & 0.06 & 0.15 & 0.12 & 0.43 \\
\hline Lwamondo & 0.01 & 0.50 & 0.4 & $0.00^{*}$ & 0.03 & 0.28 \\
\hline Mampakuil & 0.01 & 0.39 & 0.53 & $0.00^{*}$ & 0.00 & 0.87 \\
\hline Phafuri & 0.07 & 0.12 & 0.75 & $0.00^{*}$ & 0.18 & $0.01^{*}$ \\
\hline Phunda Maria & 0.05 & 0.04 & 0.62 & $0.00^{*}$ & 0.05 & $0.04^{*}$ \\
\hline Sigonde & 0.00 & 0.79 & 0.68 & $0.00^{*}$ & 0.13 & $0.04^{*}$ \\
\hline Thathe & 0.00 & 0.99 & 0.22 & $0.00^{*}$ & 0.00 & 0.77 \\
\hline Tshiombo & 0.00 & 0.64 & 0.33 & $0.00^{*}$ & 0.02 & 0.42 \\
\hline Vreemedeling & 0.00 & 0.30 & 0.33 & 1.07 & 0.00 & 0.24 \\
\hline
\end{tabular}

*significant at 5\%

\section{CONCLUSION}

This study investigated rainy season characteristics with reference to maize production in the Luvuvhu River catchment for 19232015. Rainy season characteristics of interest included onset, false onset, cessation, length of the rainy season and seasonal rainfall. The study revealed that rainy season characteristics vary spatially across the catchment between dry and wet areas. The rainy season starts early and ends late at stations situated in arid regions of the catchment, leading to a long rainy season and high seasonal rainfall amounts. Farmers in these areas can plant early, mediumterm and later maturing maize varieties. The rainy season starts late and ends early in stations located in dry areas of the catchment. Early and medium-late maturing varieties are encouraged for these areas. Sigonde, Folovhodwe and Phunda Maria may not be suitable for maize production under the current climate. Farmers in these areas might have to switch to other summer crops which require less water and can withstand long dry spells. Farmers who still want to grow maize, as it a staple crop in the region, might have to consider irrigation. Planting following the first onset is discouraged due to the high probability of false onset. There were no significant changes in rainy season characteristics for the years analysed. The study revealed that rainy season characteristics across the catchment varied, with stations situated in dry areas characterized by late onset and early cessation, short seasons, and false onset and low seasonal rainfall. The findings of this study have severe implications for food security in the Luvuvhu River Catchment area as maize is a staple crop and grown under rain-fed conditions. Information on rainy season characteristics can help farmers in decision making and avoid crop failures and low yields.

\section{ACKNOWLEDGMENTS}

The authors are grateful to the Water Research Commission (K5/2403//4) and the Agricultural Research Council Professional Development Programme for funding this work. The paper was part of a MSc study at the University of KwaZulu-Natal.

\section{REFERENCES}

AKPALU W, HASSAN RM and RINGLER C (2008) Climate variability and maize yield in South Africa: Results from GME and MELE methods. IFPRI Discussion Paper 843. International Food Policy Research Institute, Washington D.C. 12 pp.

AMBROSINO C, CHANDLER RE and TODD MC (2014) Rainfallderived growing season characteristics for agricultural impact assessments in South Africa. Theor. Appl. Climatol. 115 411-426. https://doi.org/10.1007/s00704-013-0896-y

ASSENG S and PANNELL DJ (2013) Adapting dryland agriculture to climate change: Farming implications and research and development needs in Western Australia. Clim. Change. 118 167-181. https://doi. org/10.1007/s10584-012-0623-1 
ATI OF, STIGTER CJ and OLADIPO EO (2002) A comparison of methods to determine the onset of the growing season in northern Nigeria. Int. J. Climatol. 22 731-742. https://doi.org/10.1002/joc.712

AVIAD Y, KUTIEL H and LAVEE H (2004) Analysis of beginning, end and length of the rainy season along a Mediterranean-arid climate transect for geomorphic purposes. J. Arid Environ. 59 189-204. https://doi.org/10.1016/j.jaridenv.2004.01.013

AYOADE JO (1983) Introduction to Climatology for the Tropics. John Wiley and Sons, New York.

BHATTACHARYA A (2019) Water-use efficiency under changing climatic conditions. In: Bhattacharya A (ed.) Chang. Clim. Resour. Use Effic. Plants. 2019 111-180. https://doi.org/10.1016/B978-0-12816209-5.00003-9

BYAKATONDA J, PARIDA BP, MOALAFHI DB, KENABATHO PK and LESOLLE D (2020) Investigating relationship between drought severity in Botswana and ENSO. Nat. Hazards. 100 255-278. https:// doi.org/10.1007/s11069-019-03810-1

CONRADIE DCU (2012) South Africa's climatic zones: Today, tomorrow. International Green Building Conference and Exhibition; Future Trends and Issues Impacting on the Built Environment, 25-26 July 2012, Sandton.

DURAND W ( 2006) Assessing the impact of climate change on crop water use in South Africa. CEEPA DP28. Univ. Pretoria, Pretoria.

GAUTHEIR TD (2001) Detecting trends using Spearman's rank correlation coefficient. Environ. Forensics. 2 359-362. https://doi. org/10.1006/enfo.2001.0061

GBANGOU T, LUDWIG F, VAN SLOBBE E, HOANG L and KRANJACBERISAVLJEVIC G (2019) Seasonal variability and predictability of agro-meteorological indices: Tailoring onset of rainy season estimation to meet farmers' needs in Ghana. Clim. Serv. 14 19-30. https://doi.org/10.1016/j.cliser.2019.04.002

HACHIGONTA S, REASON CJC and TADROSS M (2008) An analysis of onset date and rainy season duration over Zambia. Theor. Appl. Climatol. 91 229-243. https://doi.org/10.1007/s00704-007-0306-4

HASSAN MN and STERN RD (1988) A simple method for analysing daily rainfall data: A case study for Kota Bharu. Pertanika. 11 101106.

JEWITT GPW, GARRATT JA, CALDER IR and FULLER L (2004) Water resources planning and modelling tools for the assessment of land use change in the Luvuvhu Catchment, South Africa. Phys. Chem. Earth A/B/C. 29 1233-1241. https://doi.org/10.1016/j. pce.2004.09.020

MARTIN RV, WASHINGTON R and DOWNING TE (2000) Seasonal maize forecasting for South Africa and Zimbabwe derived from an agroclimatological model. J. Appl. Meteorol. 39 1473-1479. https://doi. org/10.1175/1520-0450(2000)039\%3C1473:SMFFSA\%3E2.0.CO;2

MASUPHA TE, MOELETSI ME and TSUBO M (2016) Dry spells assessment with reference to the maize crop in the Luvuvhu River catchment of South Africa. Phys. Chem. Earth A/B/C. 92 99-111. https://doi.org/10.1016/j.pce.2015.10.014

MOELETSI ME, SHABALALA ZP, DE NYSSCHEN G and WALKER $S$ (2016) Evaluation of an inverse distance weighting method for patching daily and dekadal rainfall over the Free State Province, South Africa. Water SA. 42 466-474. https://doi.org/10.4314/wsa. v42i3.12

MOELETSI ME and WALKER S (2012) Rainy season characteristics of the Free State Province of South Africa with reference to rain-fed maize production. Water SA. 38 775-782. https://doi.org/10.4314/ wsa.v38i5.17

MOLDEN D, VITHANAGE M, DE FRAITURE C, FAURES F, GORDON L, MOLLE F, PEDEN D and STENTIFORD D (2011) Water availability and its use in agriculture. Treatise Water Sci. 4 707-732. https://doi.org/10.1016/B978-0-444-53199-5.00108-1

MUBVUMA MT (2013) Climate change: matching growing season length with maize crop varietal life cycles in semi-arid regions of Zimbabwe. Greener J. Agric. Sci. 3 809-816.

MUGALAVAI EM, KIPKORIR EC, RAES D and RAO MS (2008) Analysis of rainfall onset, cessation and length of growing season for western Kenya. Agric. For. Meteorol. 148 1123-1135. https://doi. org/10.1016/j.agrformet.2008.02.013
MUPANGWA W, WALKER S and TWOMLOW S (2011) Start, end and dry spells of the growing season in semi-arid southern Zimbabwe. J. Arid Environ. 75 1097-1104. https://doi.org/10.1016/j. jaridenv.2011.05.011

NKUNA TR and ODIYO JO (2016) The relationship between temperature and rainfall variability in the Levubu sub-catchment, South Africa. Int. J. Educ. Learn. Syst. 1 65-75.

ODIYO JO, MAKUNGO R and NKUNA TR (2015) Long-term changes and variability in rainfall and streamflow in Luvuvhu River Catchment, South Africa. S. Afr. J. Sci. 111 (7/8) Art. \#2014-0169, 9 pp. http://doi.org/10.17159/sajs.2015/20140169

OMOTOSHO JB, BALOGUN AA and OGUNJOBI K (2000) Predicting monthly and seasonal rainfall, onset and cessation of the rainy season in West Africa using only surface data. Int. J. Climatol. 20 865-880. https://doi.org/10.1002/1097-0088(20000630)20:8\%3C865::AID-JO C505\%3E3.0.CO;2-R

PACHAURI RK, ALLEN MR, BARROS VR, BROOME J, CRAMER W, CHRIST R, CHURCH JA, CLARKE L, DAHE Q and DASGUPTA P (2014) Climate change 2014: synthesis report. Contribution of Working Groups I, II and III to the fifth assessment report of the Intergovernmental Panel on Climate Change. IPCC.

PUTH MT, NEUHÄUSER M and RUXTON GD (2015) Effective use of Spearman's and Kendall's correlation coefficients for association between two measured traits. Anim. Behav. 102 77-84. https://doi org/10.1016/j.anbehav.2015.01.010

RAES D, SITHOLE A, MAKARAU A and MILFORD J (2004) Evaluation of first planting dates recommended by criteria currently used in Zimbabwe. Agric. For. Meteorol. 125 177-185. https://doi. org/10.1016/j.agrformet.2004.05.001

REASON CJC, HACHIGONTA S and PHALADI RF (2005) Interannual variability in rainy season characteristics over the Limpopo region of southern Africa. Int. J. Climatol. 25 1835-1853. https://doi. org/10.1002/joc. 1228

SINGO LR, KUNDU PM, ODIYO JO, MATHIVHA FI and NKUNA TR (2012) Flood frequency analysis of annual maximum stream flows for Luvuvhu River Catchment, Limpopo Province, South Africa In: $16^{\text {th }}$ SANCIAHS Hydrology Symposium. 1-3.

SIVAKUMAR MVK (1988) Predicting rainy season potential from the onset of rains in Southern Sahelian and Sudanian climatic zones of West Africa. Agric. For. Meteorol. 42 295-305. https://doi. org/10.1016/0168-1923(88)90039-1

SMITH IN, WILSON L and SUPPIAH R (2008) Characteristics of the northern Australian rainy season. J. Clim. 21 4298-4311. https://doi. org/10.1175/2008JCLI2109.1

STERN RD and COE R (1984) A model fitting analysis of daily rainfall data. J. R. Stat. Soc. Ser. A. 147 (1) 1-34. https://doi.org/10. 2307/2981736

STERN RD, DENNETT MD and DALE IC (1982) Analysing daily rainfall measurements to give agronomically useful results. I. Direct methods. Exp. Agric. 18 223-236. https://doi.org/10.1017/ S001447970001379X

TADROSS M, SUAREZ P, LOTSCH A, HACHIGONTA S, MDOKA M, UNGANAI L, LUCIO F, KAMDONYO D and MUCHIND M (2007) Changes in growing-season rainfall characteristics and downscaled scenarios of change over southern Africa: implications for growing maize. In: IPCC Regional Expert Meeting on Regional Impacts, Adaptation, Vulnerability, and Mitigation, Nadi, Fiji. 193-204.

TADROSS MA, HEWITSON BC and USMAN MT (2005) The interannual variability of the onset of the maize growing season over South Africa and Zimbabwe. J. Clim. 18 3356-3372. https://doi. org/10.1175/JCLI3423.1

TONGWANE MI and MOELETSI ME (2015) Intra-seasonal rainfall variability during the maize growing season in the northern lowlands of Lesotho. Theor. Appl. Climatol. 120 575-585. https://doi. org/10.1007/s00704-014-1183-2 